\title{
Design Concept of Electric Vehicle Ambulance
}

\author{
Dirk van Gogh ${ }^{1}$, Kiyomoto Kawakami ${ }^{2}$, and Hiroshi Shimizu ${ }^{3}$ \\ ${ }^{1}$ Department Academy, Hogeschool Gent, Ghent University Association, dirk.vanGogh@hogent.be \\ ${ }^{2}$ Faculty of Environmental Information, Keio University, kiyomoto@sfc.keio.ac.jp \\ ${ }^{3}$ Faculty of Environmental Information, Keio University, hiros@sfc.keio.ac.jp
}

\begin{abstract}
Today's emergency transportation by internal combustion engine ambulances has many problems: it has a high vibration for the patient and the medics, it has a limited size of workstation for the medical treatment, it slowly accelerates with jolts and it has a high floor base which makes driving unstable while cornering. An Electric Vehicle ambulance, EV ambulance, is proposed to solve all this problems. The structural design of today's ambulance is compared with the design concept of an EV ambulance. The EV component technologies of an in-wheel drive, component built-in frame and tandem suspension system are applied to the EV ambulance.

Four types of ambulances are presented: one based upon the average outer dimensions of a conventional ambulance, second based upon the average inner dimensions of workspace of the medics, third with a driver seat in the middle of the cabin and finally with a diver seat on an elevated position. A dual direction drive is applied in the ambulance and one type of $E V$ ambulance its length is reduced to $2 m$ so that it can enter into buildings. The EV ambulances illustrate that a smooth vibration and high acceleration of $0,4 G$ is reached, the noise inside the cabin is reduced from 90dbA to 60dbA; the floor height is reduced from $50 \mathrm{~cm}$ to $30 \mathrm{~cm}$, $85 \%$ of the total inner space can be used as a workspace, and stable drive and cornering is most efficient during an emergency transportation.
\end{abstract}

\section{Keywords}

electric vehicle, design, modeling, safety

\section{INTRODUCTION}

In daily life ambulances are important [Khalid, 2002] when traffic accidents, sudden sickness, or sickness who can not move by themselves occurs. The requirements of ambulance are to carry the patients softly, quickly and with first medical treatment. A conventional ambulance has been not effective for such purpose because it vibrate when it runs, it slowly accelerates, which is not useful for first medical care because of its small space on the cabin. From these reasons, the effectiveness to use an internal combustion engine car (ICE) as an emergency vehicle is low [Proceedings H. F.et al.,1986]. To solve this problems, an electric vehicle (EV) need to be introduced into the automotive market that is important for our environment as well as for a more comfortable traffic [van Gogh et al., 2001]. Also in regard to its specific 'help rendering' service in human mobility we believe that an EV ambulance is most suitable for public acceptance. Based upon the results of previous EV research, where the EV technology was already applied in 'KAZ', Keio Advanced Zero Emission Vehicle, a high performance electric vehicle [Shimizu et al., 2001], a concept is chosen that involves an EV ambulance. In this paper, the way to apply EV technology to an ambulance is proposed and many types of design concepts of an EV ambulance are presented so that all the innovating elements of an EV ambulance can be demonstrated as well as its broad application in today's High-Tech Urgent Medical Care can be shown.

\section{CONVENTIONAL AMBULANCE \\ 2.1 Operation of the ambulance}

Within the actual health care system, ambulances are poorly equipped, because its structure is a conversion of an ICE small van with a hard suspension. Indeed, when an ICE vehicle is applied, it is the easiest way to make room for a patient in the vehicle [Shimizu, 1995]. For this reason an ambulance has an extremely low comfort for the patient, has specific problems for medical treatment during the transportation and has a performance defect that makes quick and safe driving impossible [Crown et al., 2002].

An ambulance has two important functions. First of all it is the only transportation tool in case of health emergency. Secondly it is a moving working space for medics who are saving the life of a patient. As a transportation tool, the average driving range of an ambulance, for example in Japan, is short. The distance is $8 \mathrm{~km}$ from the fire-brigade to the patient, from the patient to the hospital it is $10 \mathrm{~km}$ and from the hospital to the firebrigade it's $15 \mathrm{~km}$ [Butler, 1996]. Between missions the ambulance waits more than 20 minutes at the hospital for checking the health of patient, make a report for 
the aid and to get an acceptance from a doctor and to prepare the ambulance for the next mission. After this time, the ambulance returns to the fire-brigade. The average crew consists of three medics: one who is the driver, the second who is the co-driver on the way to go to an emergency and who also assists the patient on its transportation, and a third assistance medic, preparing the equipment inside the cabin and taking care of a patient until they arrive at the hospital where a doctor takes over.

\subsection{Negative effect of emergency transportation}

The vibration of today's ambulances, due to the internal combustion engine, and suspension system, is anything but comfortable for a patient who can be in critical condition. Also for the crew who take care of the patient and who is responsible for the first urgent medical treatment inside the ambulance, there are negative effects. Indeed, the crew has to work in vibrating circumstances which of course makes the treatment less efficient and increases its tiredness. Moreover it reduces the safety, the concentration and efficiency of the medical tasks. In case of a long exposure to vibration, health damage for patient and crew is a problem.

The acceleration of the ambulance is not smooth and even poor because it happens with jolts for the reason that there are four or five interruptions during the transmission to higher speed. Even in automatic transmission ambulances, the acceleration power is low.

The power of the engine is too small to accelerate because it is heavier than normal similar sized vans due to the weight of the medical equipments. In internal combustion engine vehicles there is a limited workspace for the medics, because the engine system and axle housing under the floor takes a lot of space. This limits the space for medical equipment and the work space for the medic. When older patients want to get in or out by themselves, a small two step staircase must be installed to help them, due to the high floor of the cabin. For the medics there is additional load because they have to lift the stretcher into the ambulance.

\subsection{Structure of ambulance and its problems}

Actually an ambulance with its average floor height of $50 \mathrm{~cm}$ is considered as a high floor and an unstable structure [Coats, 2002]. Due to the weight of the medical equipment inside the ambulance, the standing or half standing working positions of the crew and the weight of the patient on a bed that is $1 \mathrm{~m}$ high from the floor the ambulance is not safe while cornering. All of this results in a higher centre of gravity of the ambulance which entails a higher risk of skidding while taking turns.

Inside the cabin of an ICE Ambulance there is a noise pollution because the actual level of noise inside is be- tween $88 \mathrm{dbA}$ and $90 \mathrm{dbA}$ when the ambulance is made by Chevrolet and achieves $87 \mathrm{dbA}$ when it is made by Mercedes. [Lindenberg, 1988] The vibration of today's ambulances, due to the motor and suspension system and due to the transmission from the axles to the rear wheels under the floor, brings out specific problems. For a patient, who could be in a critical condition it is anything but comfortable. An ICE ambulance its NO2 and SPM (Suspended Particular Matter) emission has an negative effect on the air pollution and increases the environmental pollution. Finally, today's basic structure of actual ambulances is not convenient for the patients, medics, and medical equipment, neither is it possible to drive quickly while keeping it safe.

\section{RECENT DEVELOPED EV TECHNOLOGY} 3.1 Useful technology for the ambulance's structure

By using recently developed original technologies there is maximum integration [Shimizu et al., 2001] and the cabin space is greater than before. The 'In Wheel Drive System' (IWDS) neglects the engine room and its transmissions, because it integrates the energy system, motor, gear and brake. Thanks to its combined system, it has high efficiency, light weight and increase the space on the cabin.

The 'Component Built-in Frame' (CBF) where all batteries and components are inserted into the structure under the floor makes the space wider in the cabin, offers a lighter weight because frame structure can be used for the battery case and offers totally a lower centre of gravity. The energy storage is on the batteries under the floor and a wheel axle can be installed anywhere on this CBF, so that it offers different concept design of chassis's and a highly flexible styling design. The 'Tandem Wheel Suspension System' (TWSS) spreads the load of over two smaller wheels in stead of one wheel. Also this innovation offers a wider space thanks to the smaller tires. It offers an optimal vibration and low noise and a high grip while cornering. Moreover, this fine component of EV technology makes it possible to optimise the emergency transportation as well as it improves the workspace for the medics.

The same as it is applied in KAZ in 2001, a Li-ion battery is used which has a very high energy and is highpower compared to conventional lead acid battery. By using Li-ion battery, the range per charge increased dramatically. The other merit of Li-ion battery is that its charging time is less than 20 minutes. It means it can be recharged when an ambulance is waiting in the hospital.

\subsection{Merits of KAZ's concept for the operation of an emergency transportation}

The effect of the application of the Tandem Wheel Suspension System is big to decrease the vibration. Be- 
cause the power source can be distributed over all the wheels, and due to the maximum integration of energy management, a high and smooth acceleration of the vehicle can be guaranteed. As a consequence, no jolts will disturb the medics and the transportation of the patient will be very comfortable. Thanks to the effect of its low centre of gravity of $40 \mathrm{~cm}$ to $50 \mathrm{~cm}$ high, there is small roll while cornering which is comfortable for the patient as well for the medical aid. All these above mentioned technologies: IWDS, CBF and TWSS are useful to improve the work space and to get in and get off very easily. For the medical crew is getting in or out with a stretcher no physical load because the lift is less than $30 \mathrm{~cm}$ high. The reached flat floor of the chassis makes it possible to foresee more space for first needed medical equipment.

\subsection{Added values by using the technology of KAZ}

A dual direction driving mode (DDD) can be reached on an EV ambulance, because the position of the doors can be put anywhere on the chassis, as can be seen in Figure 1, and the quick transportation to the front or the back which drives equally fast forwards as it does in reverse. It is even possible to put in two driver seats, one at the front and one at the back of the ambulance, which improves the entrance and exit efficiency of patient, assistants and tools at any side of the vehicle.

Thanks to the no noise and no emission characteristic of an EV, its simple and flexible frame structure, its high space efficiency of the cabin, an EV ambulance can be modified to an small-sized vehicle so that it can enter into buildings. An EV ambulance can go into very narrow places so that medics can be brought within very close range of the actual place of accident. The possibility to drive in and out of narrow streets quickly without turning the vehicle offers a high operation speeds which is important factor in emergency services.

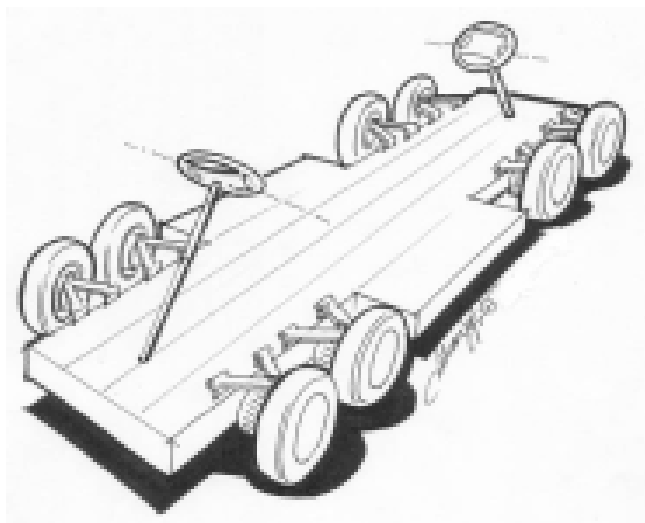

Fig. 1 Concept of Dual Direction Drive

\section{DESIGN CONCEPTS OF AN EV AMBULANCE 4.1 Methodology}

Given the multitude of cultural and functional uses across the different continents -in the U.S. f.i. limited aid is given inside the ambulance as well as on the actual spot of the accident, while in Europe as much medical assistance as possible is supplied on the place of the accident itself - the new concept has to have maximal flexibility to offer a formal answer to the great variety in cultural and functional uses per country and per region. Ambulances to transport several patients and ambulances only equipped with medical instruments do therefore not belong to this structural design.

The basic vehicle type that is considered as a standard of an ambulance bearing the closest resemblance to this basically concept is: a vehicle identified as an ambulance, and designed and equipped for the transport, basic treatment and monitoring of patients so that there is a maximum respect for actual measurements and standardisation as shown in Table 1, which illustrates the basic standard of capacity for an ambulance. Therefore a maximal integration of function and technology gives highly space in all new design proposals for ambulances.

Table 1 Basic standard of capacity for an ambulance

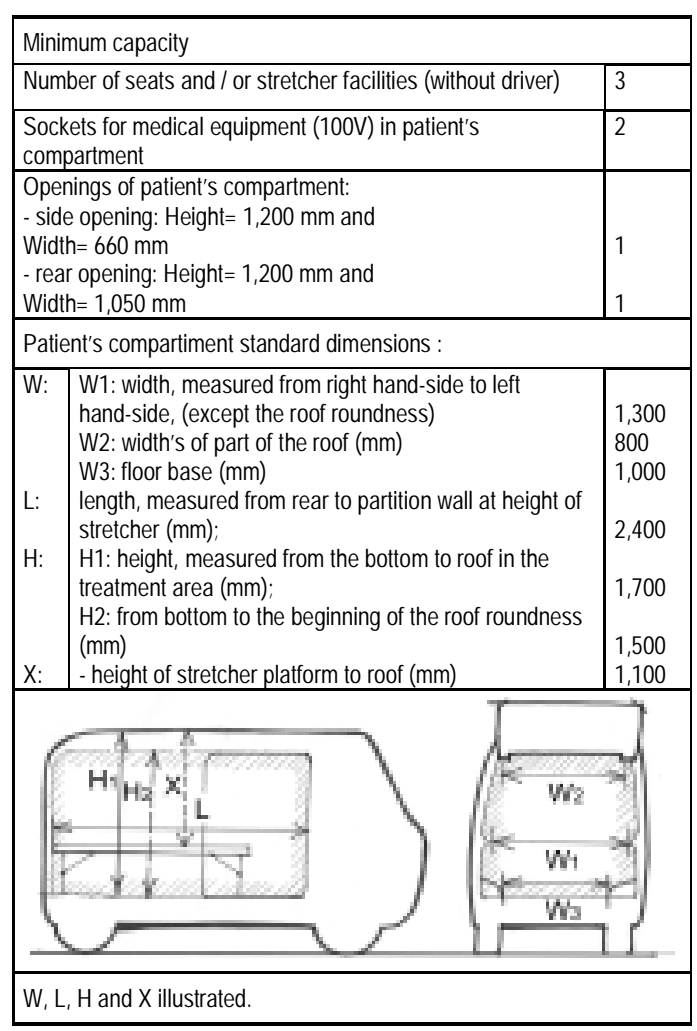

4.2 Four types of packaging design of an ambulance Based upon the average outer dimensions of an conventional ambulance, based upon the average inner dimen- 
sion of workspace of the medics, included its equipment and based upon the maximum volume of room space on a EV chassis, four proposals of a vehicle type are originated. The driver seats can be changed and, various types of ambulances can be made. Fixed front and back seats, folding front and back seats, a seat in the middle of the cabin or seats on an elevated position are designed.

\subsubsection{Type A: based upon outer dimension}

On the first packaging design, the dimensions of the exterior measurements of an average contemporary ambulance are maintained, a fixed front and back seat for the driver is installed as shown in Figure 2. Thanks to the technological innovations more inner space is ameliorated and it shows that compared with a conventional ambulance more medical equipment and paraphernalia can be taken along to the place of accident.

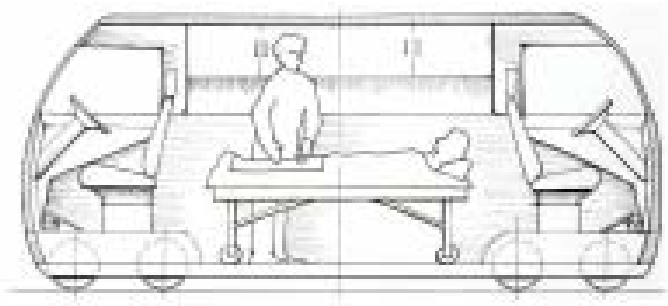

(a) side view of type A

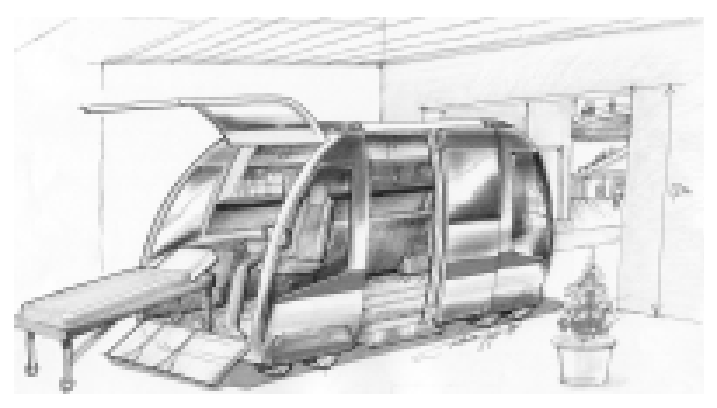

(b) perspective of type A

Fig. 2 Type A, based upon outer dimensions

\subsubsection{Type B: based upon inner dimension}

The second packaging design offers the opportunity of maintaining the average amount of inner space these day's.

This entails that smaller outer measurements are achieved compared to contemporary ambulances, so that it can offer a very high accessibility of patients involved in accidents inside buildings, narrow alleys, and small entrances as well. As shown in Figure 3, the packaging design illustrates that the outer size of a conventional ambulance can be reduced and the workspace of the medic can be maintained.

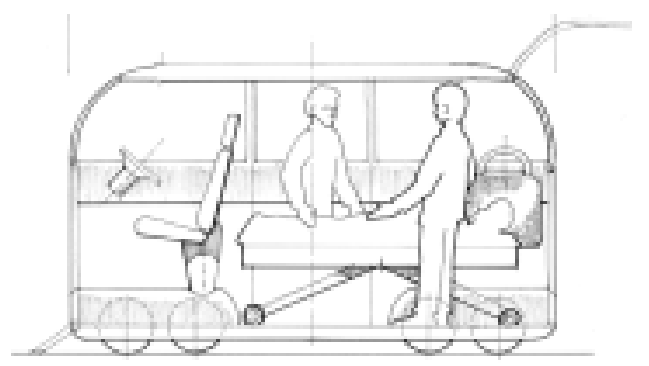

(a) side view of type B

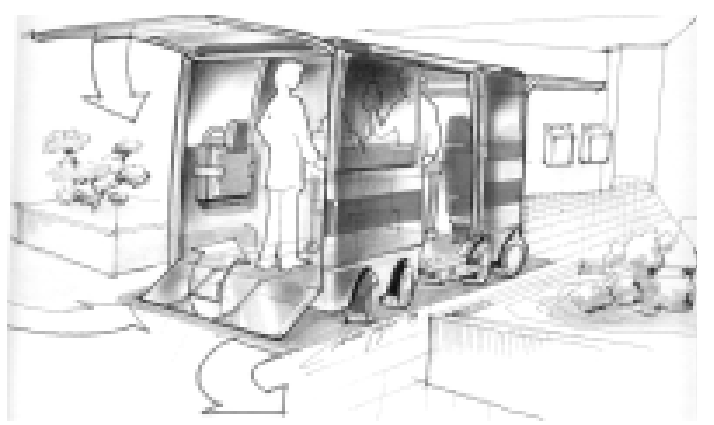

(b) perspective of type $\mathrm{C}$

Fig. 3 Type B, based upon inner dimensions

\subsubsection{Type C: driver's seat in the middle}

On the third packaging design as shown in Figure 4, it shows an application where the driver directly communicates with the medics in the middle of the cabin.

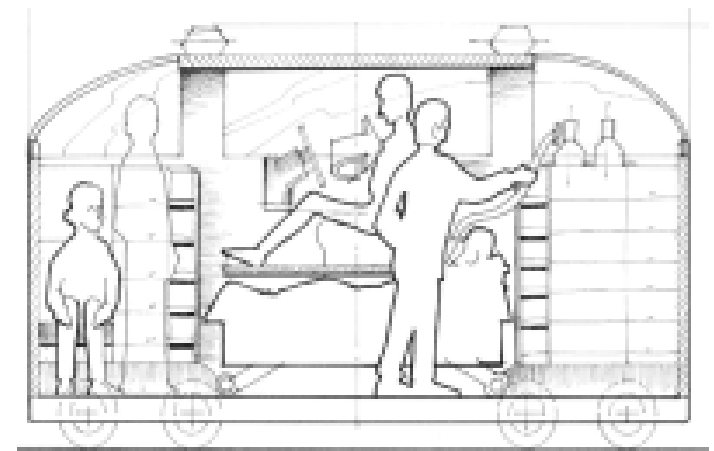

(a) side view of type $\mathrm{C}$

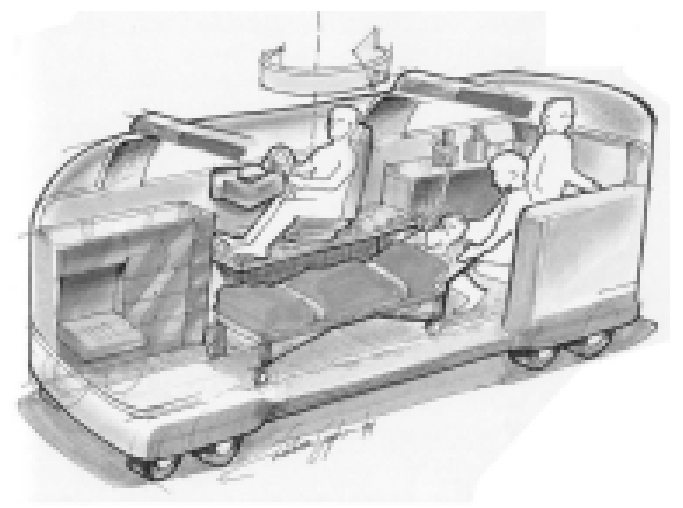

(b) perspective of type C

Fig. 4 Type C: driver's seat in the middle 
Taking into account the attentiveness of the ambulance driver is absolutely vital in dense traffic area's, the chauffeur's driving behaviour and the driving style needs to be adapted in function of the advice coming from the medics during transit. Furthermore the advantages of dual direction driving keep good as a change of direction of traffic can be effected while reversing the complete steering post stationed in the middle.

\subsubsection{Type D: driver's seat on an elevated position}

On the fourth packaging design as shown in Figure 5, it shows an application where it is possible to provide a maximal medical equipment in the inner space of the ambulance. The elevated position also ameliorates the sight on busy main roads and populated areas.

On the other hand this vehicle offers an extra possibility by folding up one of the two steering controls so that patient and crew can have a maximal user space at their disposal. In areas where a lot of accidents happen this type offers a solution. Thanks to its central medical work post that can smoothly be loaded as well as unloaded fast interventions are possible, with one and the same vehicle.

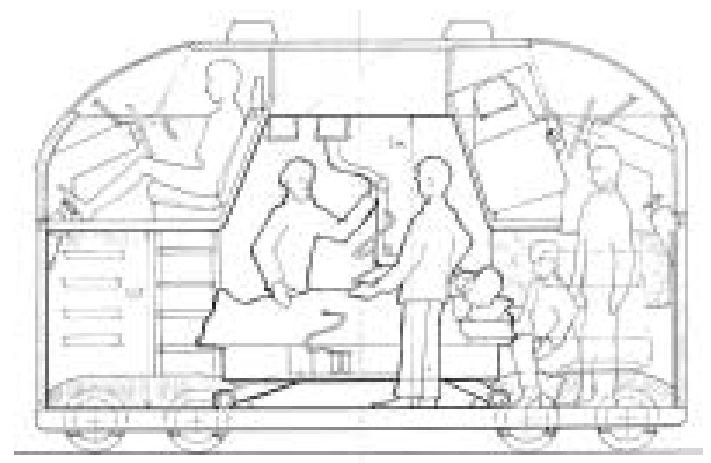

(a) side view of type $\mathrm{D}$

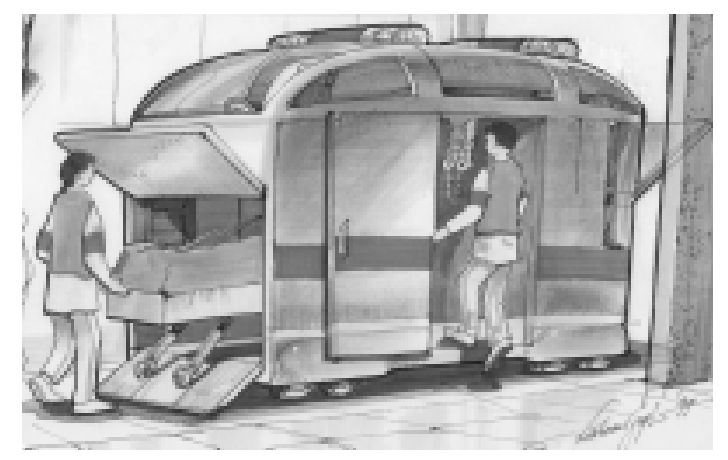

(b) perspective of type D

Fig. 5 Type D, driver's seat on an elevated position

\subsection{Detailed performance of an $\mathrm{EV}$ ambulance}

The basic specification is based upon the actual emergency service. For this reason today's references are: one bed in the cabin, the medical instruments, specific for a first aid kid, which are put on the walls and the maximum speed which is $150 \mathrm{~km} / \mathrm{h}$ and a minimum range of $100 \mathrm{~km}$. Moreover, front and back driving is added on the acceleration rate which is more than $0.3 \mathrm{G}$.

Starting from the above mentioned standards and taking the absence of motor space into consideration the positions of driver on type A, B, C and D, medical staff and patient can freely be determined. We can select either design depending an the actual situation at hand. Considering the total inner dimension of the EV ambulance and the inner workspace for the medics, the cabin space efficiency is $85 \%$ which is almost $10 \%$ better as an conventional ambulance. As is shown on Table 2, different measurements of the proposals are compared. Except the EV ambulance type B, all the proposals offer a better workspace for the medic compared with the standard of a normal ambulance.

Table 2 Measurements of the four types of ambulance

\begin{tabular}{|c|c|c|c|c|}
\hline \multicolumn{5}{|c|}{$\begin{array}{c}\text { Measurements inside; } \\
\text { Patient's compartment dimensions: }\end{array}$} \\
\hline \multicolumn{5}{|c|}{$\begin{array}{l}\text { Width, measured from right handle-side to left hand-side, (except the } \\
\text { roof roundness): }\end{array}$} \\
\hline & Type A & Type B & Type C & Type D \\
\hline $\mathrm{W}:(\mathrm{m})$ & 1,5 & 1,5 & 1,5 & 1,5 \\
\hline $\mathrm{W}$ of roof & 1,2 & 1,2 & 1,2 & 1,2 \\
\hline W of floor base & 1 & 1 & 1 & 1 \\
\hline \multicolumn{5}{|c|}{ Length, measured from rear partition wall at height of stretcher: } \\
\hline $\mathrm{L}:(\mathrm{m})$ & 4,6 & 3,3 & 4,3 & 4,3 \\
\hline \multicolumn{5}{|c|}{$\begin{array}{l}\text { Height, measured from the bottom to roof in the treatment area; } \mathrm{Hb} \text { : } \\
\text { from the bottom to beginning of the roof roundness: } \\
\text { Xstr: height of stretcher platform to roof }\end{array}$} \\
\hline $\mathrm{H}:(\mathrm{m})$ & 1,9 & 1,7 & 2,2 & 2,8 \\
\hline $\mathrm{Hb}:$ & 1,7 & 1,6 & 1,9 & 2,0 \\
\hline X str. & 1,5 & 1,3 & 2,0 & 2,3 \\
\hline
\end{tabular}

The expected performance of the electronic components and the body are shown in Table 3. The motor performance can be achieved by Brushless-DC motor type, of which the weight is about $20 \mathrm{~kg}$. The battery perfor-

Table 3 Expected performance of the EV ambulance

\begin{tabular}{llll}
\hline Motor: & & \\
\hline & Maximum torque & 50 & $\mathrm{Nm}$ \\
Maximum speed & 12,000 & $\mathrm{rpm}$ \\
Base velocity & 8,400 & $\mathrm{rpm}$ \\
Maximum power & 44 & $\mathrm{~kW}$ \\
Gear ratio & 5.769 & \\
Number of motor & 8 & \\
\hline Type & 0,4 & $\mathrm{G}$ \\
Capacity & $\mathrm{Li}-\mathrm{ion}$ & \\
\hline Maximum acceleration: & 40 & $\mathrm{kWh}$ \\
\hline Maximum range: & 100 & $\mathrm{~km}$ \\
Maximum Speed: & 150 & $\mathrm{~km} / \mathrm{h}$ \\
Diameter of the tires: & 400 & $\mathrm{~mm}$ \\
Gross Weight: & 2,500 & $\mathrm{~kg}$ \\
\hline Efficiency: & & \\
Coefficient of air drag & 0.5 & \\
Coefficient of Rolling & 0.008 & \\
resistance & $92 \%$ & \\
Gear efficiency & 4.0 & $\mathrm{~m}^{2}$ \\
\hline
\end{tabular}


mance can be achieved by Li-ion battery of which the anode is $\mathrm{MnO} 2$. On the following chart an overview is given about the detailed specifications.

The performance of the motor is set by a motor maximum torque of $50 \mathrm{Nm}$, a maximum speed of 12,000rpm, a base velocity of $8,400 \mathrm{rpm}$, a maximal power of 44 $\mathrm{kW}$, and gear ratio of 5 . The expected performance of the EV ambulance is shown in Figure 6 and Figure 7.

The acceleration of the vehicle is $0.4 \mathrm{G}$ when its weight is $2,500 \mathrm{~kg}$ as is shown in Figure 6. A maximum speed of $158 \mathrm{~km} / \mathrm{h}$ can be reached at the rolling resistance of 0.008 , an air drag constant of 0.5 and a frontal area of $4 \mathrm{~m}^{2}$. The acceleration of $0.4 \mathrm{G}$ means about 4 times quick acceleration compared with the normal acceleration of automobiles in the city. Then the acceleration performance of the EV ambulance is good enough for emergency uses.

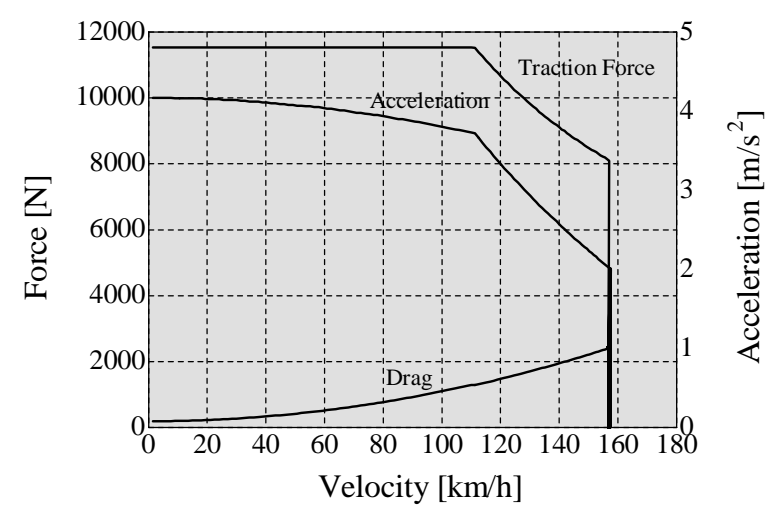

Fig. 6 Driving performance curve of the EV ambulance

Figure 7 shows the EV ambulances reach to $100 \mathrm{~km} / \mathrm{h}$ after 4 seconds of the start and it takes 15 seconds to drive $400 \mathrm{~m}$ from the start. These performances are sufficient enough to could be used for emergency transportation.

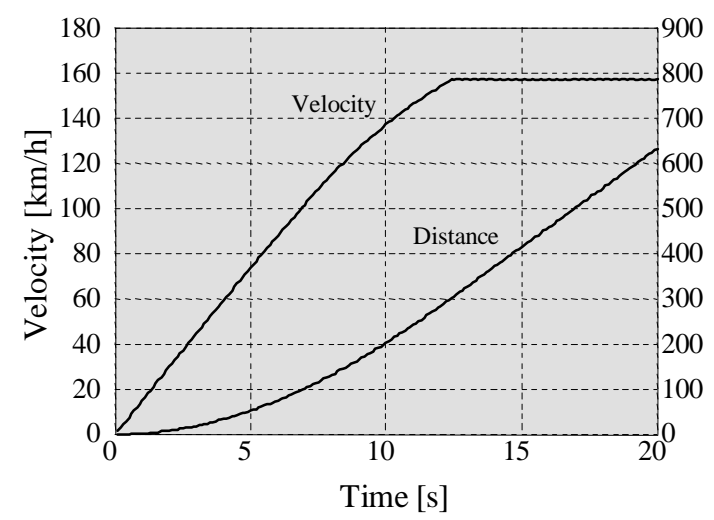

Fig. 7 Time versus velocity and distance of the EV ambulance

\section{CONCLUSION}

The emergency transportation by conventional ambulances still has a lot of negative effects for the patient, the medics, and the driver. Thanks to the recently developed EV technology this problems are solved: a low and completely flat floor is generated, a no noise and smooth vibration, a high acceleration and a high operation speed is reached an efficient capacities of buildings, for the medics to be brought within very close range of the actual place of accident, to make a wider interior space for the first urgent medical equipment and for the working space of the medics. It illustrates a quick transportation to the front or the back for offering a quick emergency service. Finally, EV technology is a grateful item for designers, because it offers the facility to create concepts which give real answers to optimise the possibilities of reaching a maximum in daily life comfort and in environmental health. EV technology of CBF combined with the IWDS and TWSS results in the most reliable vehicle system when human life is at stake. Consequently ergonomically workspace for the medics is originated and new added values are shown. The specific dimensions of EV ambulances make it possible to drive into narrow streets, to use the drive-in capacities of buildings, for the medics to be brought within very close range of the actual place of accident, to make a wider interior space for the first urgent medical equipment and for the working space of the medics. It illustrates a quick transportation to the front or the back for offering a quick emergency service.

Therefore it is necessary to start the introduction of EV ambulances in today's market so that the world wide consumers can be satisfied with EV's innovative effects when put into reality.

\section{References}

Butler Jo Elizabeth, Major Global Review of cooperative System of Health and Social Care Completed, Information Support Unit of the United Nations Department for Policy Coordination and Sustainable Development (DPCSD), Vol. 2, Issue 6, 1996.

Coats, T. J., Prehospital care for road traffic casualities, Clinical review, BMJ 324, 1135-1138, 2002.

Crown Copyright, National Health Services, Ambulance Services, England 2001-02, Bulletin 2002/13, 2002.

Khalid Shibib, Emergency Preparedness and Response Highlights, Department of Emergency and Huminitarion Action, World Health Organization, Vol. 1, No. 5, 2002.

Lindberg L, National Board of Occupation Safety and Health, Solna, Noise and vibrations in ambulance vehicles and incubators, 1988. 
Proceedings of the Human Factors Society 30th Meeting, Dayton Ohio, Human Engineering Concerns in Ambulance Interior Design, The Human Factors Society, Santa Monica, 345-348, 1986.

Shimizu, H., K. Kawakami, Y. Kakizaki, S. Matsugaura, M. Ohnishi, and D. van Gogh, 'KAZ the Super Electric Vehicle', Symposium Proceedings of The 18th International Electric Vehicle Symposium, 245-248, 2001.

Shimizu, H., The National Institute for Environmental Studies, Japan, A Proposal for Sustainable Development: The Asia car, Global Environmental Problem Proposal Competition, Proposal-Toward a Lasting Earth Award Winning Proposals, Scientific abstract 21st Earth Awards, 1995.

van Gogh, D., H. Shimizu, and J. Norek, Design Concept of High Performance Electric Vehicle "KAZ”, Bulletin of JSSD, The Science of Design, Vol. 49, No. 6, 27-36, 2003.

(Received April 11, 2005; accepted June 20, 2005) 